\title{
Influence of visual analysis skills and collaborative work on modelling activities in web-based learning environment
}

\author{
Jérémy Castéra, Tago Sarapuu, Jaanika Piksööt \\ Science Education Centre, University of Tartu
}

\begin{abstract}
The goal of this study is to analyse the influence of the visual analysis skills on the student modelling activities in a web-based learning environment. The influence of collaborative work was also tested. Thus, 131 French high school students working individually and 116 in pairs used the environment Cell World. The environment recorded the outcomes of a sequence of modelling operations into log-files. The students' visual analysis skills were assessed individually in pre- and post-tests. The analysis of the log-files has shown that cooperative work allows better performances at the very beginning of the modelling sequence. However, the difference of performances between collaborative and individual workers is not anymore different during the rest of the following operations. The results show also that low-performing modellers are lower in visual analysis skills than highperforming modellers.
\end{abstract}

Keywords - visual analysis skills, collaborative work, webbased environment.

\section{Introduction}

\subsection{Collaborative $v s$. individual work}

Different studies have proved the effectiveness of environment designed for collaborative use on learning skills. Just to cite some of recent works, Noroozi et al. [1] have shown how computer-supported collaborative learning improves the quality of students' knowledge construction. Stegmann et al. [2] have demonstrated the positive effect of computer-supported collaboration scripts on argumentative knowledge construction, and Raes et al. [3] have proved the effect of such environment on specific knowledge acquisition and metacognitive awareness. However, to our knowledge, few studies have tried to compare the dyadic (face-to-face) and individual students' achievements in virtual environments designed for individual use. In this way, Kolloffel et al. [4] have shown that collaborative learners outperform individuals regarding to a knowledge post-test after using environment with no special design for collaborative work. This result confirms that collaboration (even without special design for group work) fulfils a scaffolding function in learning and task solving. As explained by Gijlers and de Jong [5], collaborative work is recognized by the scientific community as a learning enhancer. They have explained that for collaborative solving tasks, students have shared and confronted their hypotheses. It means that inside the cooperative groups, students stimulate each other by trying to find the adequate solution.

\subsection{Visual analysis skills}

The report $21^{\text {st }}$ Century Skills: Literacy in the Digital Age [6] has explained that one essential component of students' visual literacy is the 'understanding of basic elements composing visual design, technique and media'. More precisely, students who have high level of visual analysis skills to identify the components are able to understand the whole representations presented by visual media. That is why the prior level of visual information analysis should facilitate or obstruct modelling activities in learning environment (as visual media). Moreover, the use of digital environment enhances the visual literacy skills of students by training them to develop interpretations of new representations [7].

The goal of our study proposes to explore the influence of the visual analysis skills and collaborative work on modelling activities in a web-based learning environment. In this study, we used Cell World (http:/bio.edu.ee/models/en/), a web-based learning environment where students have to realise several modelling operations in order to study about protein synthesis.

\section{Research questions and hypotheses}

The present study tried to find answers to the following research questions:

Do the cooperative workers perform better than individuals in modelling operations?

Does the prior level of analysis of visual information influence the modelling operations?

According to the literature, two main hypotheses can be drawn: (i) Collaborative learners perform better in modelling activities because of the peer scaffolding. (ii) Higher prior level in visual analysis skills has a positive influence on student performance in modelling activities.

\section{Methods}

\subsection{Modelling operations}

In this study, students have to perform six modelling operations (or modelling activities) where they have to add a correct molecule in order to continue an animation of protein synthesis process. After each modelling operation, they have to answer a question prompt ( 5 in total, there is no question after the last operation) supporting students' understanding of crucial knowledge of protein synthesis. The model, named Traduction (http://bio.edu.ee/models/fr/), was used in French language by secondary school students.

\subsection{Participants}

The experimentation was conducted with 16- to 18 -year old 
students of 9 different schools in France - 131 worked individually and 116 in collaboration (in pairs face-to-face). Individual and collaborative workers were selected randomly by teachers. First, all the participants filled-in individually a pre-test assessing their prior level in the analysis of visual information and after the application of the model, a post-test to assess their development in visual analysis skills.

\subsection{Data collection}

The results of learners' modelling activities were recorded in the log-files of the web-based environment. This data allowed tracing back the correctness of modelling operations.

Moreover, students had to fill-in individually a pre- and post-test to assess their level in analysis of visual representations. An external representation, presented in the pre- and post-test, was a screenshot of the model used during the modelling activities. Students were assessed on the basis of total of 10 biological components composing the external representation of the pre- and post-tests (maximum of 10 points - one point per component).

\section{Results and discussion}

All the following results are based on the analysis of the modelling activity log-files and pre- and post-test measuring visual analysis skills.

\subsection{Individual vs. collaborative work in modelling activities}

In order to compare individual and collaborative workers about their performances in modelling activities, the percentage of students who made at least one mistake for each operation were calculated (Table 1).

Table 1. Number of students working individually or collaboratively that made mistakes during the sequence of six modelling operations (Op1 to Op6).

\begin{tabular}{|c|c|c|c|c|c|c|c|}
\hline & & \multicolumn{6}{|c|}{$\begin{array}{l}\text { Number of individual and collaborative workers who } \\
\text { made mistake(s) in each modelling operation }\end{array}$} \\
\hline & & Op1 & Op2 & Op3 & Op4 & Op5 & Op6 \\
\hline $\begin{array}{l}\text { Individua } \\
(\mathrm{n}=131)\end{array}$ & & $15(11 \%)$ & $2(2 \%)$ & $2(2 \%)$ & $1(1 \%)$ & 0 & 0 \\
\hline $\begin{array}{l}\text { Collabor: } \\
(\mathrm{n}=116)\end{array}$ & & $1(1 \%)$ & $4(3 \%)$ & $1(1 \%)$ & $1(1 \%)$ & 0 & 0 \\
\hline \multirow{2}{*}{$\begin{array}{l}\text { Mann- } \\
\text { Whitney } \\
\text { test }\end{array}$} & $\mathrm{p}$ & $<0.05$ & n.s. & n.s. & n.s. & n.s. & n.s. \\
\hline & Z & -2.42 & -0.72 & -0.01 & -0.5 & 0 & 0 \\
\hline
\end{tabular}

The table 1 shows that for the first modelling operation (Op1), $11 \%$ of individual workers made at least one mistake, whereas only $1 \%$ of collaborative workers were mistaken. The difference between both groups of students is statistically significant for the first operation (Mann-Whitney U-test, $\mathrm{p}<$ 0.05; $Z=-2.42$ ). Subsequently, for all the other modelling operations (from Op2 to Op6), there is no significant difference between collaborative and individual workers. From the second $(\mathrm{Op} 2)$ to the fourth (Op4) operation, just few students in both groups still have made mistakes. For the operation five (Op5) to six (Op6), there is no mistakes anymore for both groups. Another study [8], based on the same environment, has shown that the reduction of mistakes in modelling operations is due to the support of question prompts which focus learners' attention on the important aspects of the modelling operation tasks. The first question prompt displays just after the first operation. In this way, for individual workers, mistakes in modelling decrease strongly at the second modelling operation; the first question prompt furnishes a support to solve the second modelling operation (Op2). In the case of collaborative work, the rate of mistakes for the first operation is already very low and collaborations fulfil scaffolding support for modelling operations without question prompt.

\subsection{Visual analysis skills of learners before and after modelling activities}

According to the pre- and post-test, the level of individuals and collaborative learners' visual skills is similar before and after the modelling activities. Therefore, we can consider that groups of students working in collaboration or individually start the modelling activities with the same level of visual analysis skills (no significant difference: $\mathrm{Z}=$ $-1.14 ; \mathrm{p}=\mathrm{n} . \mathrm{s}$.). The post-test does not show also any significant difference between individual and collaborative workers $(\mathrm{Z}=-1.31 ; \mathrm{p}=\mathrm{n}$.s.). Thus, the modelling activities seem to have the same impact on the individual and collaborative groups. In both cases, students gain almost two points in analysis of visual information after the use of the environment.

Table 2. Pre- and post-test results of visual analysis skills of students that applied the model individually or in collaboration.

\begin{tabular}{|c|c|c|c|c|c|}
\hline \multirow{2}{*}{ Skills } & & \multirow{2}{*}{$\begin{array}{l}\text { Individua } \\
1(n=131)\end{array}$} & \multirow{2}{*}{$\begin{array}{l}\text { Collaborative } \\
\qquad(\mathrm{n}=116)\end{array}$} & \multicolumn{2}{|c|}{$\begin{array}{c}\text { Mann- } \\
\text { Whitney test }\end{array}$} \\
\hline & & & & $\mathrm{Z}$ & $\mathrm{p}$ \\
\hline \multirow{2}{*}{$\begin{array}{l}\text { Analysis skills } \\
\text { in pre-test } \\
(\max =10)\end{array}$} & Mean & 6.59 & 6.28 & \multirow[t]{2}{*}{-1.14} & \multirow[t]{2}{*}{ n.s. } \\
\hline & SD & 2.15 & 2.12 & & \\
\hline \multirow{2}{*}{$\begin{array}{l}\text { Analysis skills } \\
\text { in post-test } \\
(\max =10)\end{array}$} & Mean & 8.42 & 7.96 & \multirow[t]{2}{*}{-1.31} & \multirow{2}{*}{ n.s. } \\
\hline & SD & 1.81 & 2.22 & & \\
\hline
\end{tabular}

\subsection{Relationship between visual analysis skills and modelling activities}

Among the collaborative and individual workers, the total number of students, who made at least 1 mistake during modelling activities, was 25 . We have called this group of 25 students 'low-performing modellers', comparing to the rest of students - 'high-performing modellers', who did not make any mistake in the modelling activities. These two groups have been compared according to their prior and posterior levels of visual analysis skills (see Table 3). Results show that highperforming modellers obtained in pre-test analysis skills 6.6 
out of 10, whereas low-performing modellers got only 4.7. This difference of almost two points is strongly significant $(\mathrm{Z}$ $=-4.33 ; \mathrm{p}<0.001)$.

This result suggests that visual analysis skills influence strongly the outcome of modelling activities in a web-based learning environment. Pedaste and Sarapuu [9] have already shown that multiple factors, for instance the initial level of problem-solving skills of learners, influence outcomes of solving problems in a web-based learning environment. This study demonstrates that initial level of visual analysis skills is also an important factor influencing the student performances in virtual learning environments.

Table 3. Pre- and post-test results of the groups of high- and lowperforming modellers about visual analysis skills.

\begin{tabular}{|c|c|c|c|c|c|}
\hline \multirow{2}{*}{ Skills } & & \multirow{2}{*}{$\begin{array}{c}\text { High- } \\
\text { performing } \\
\text { modellers } \\
(\mathrm{n}=222) \\
\end{array}$} & \multirow{2}{*}{$\begin{array}{c}\text { Low- } \\
\text { performing } \\
\text { modellers } \\
(\mathrm{n}=25)\end{array}$} & \multicolumn{2}{|c|}{ Mann-Whitney test } \\
\hline & & & & Z & $\mathrm{p}$ \\
\hline \multirow{2}{*}{$\begin{array}{l}\text { Analysis skills } \\
\text { in pre-test } \\
(\max =10)\end{array}$} & Mean & 6.64 & 4.70 & \multirow[t]{2}{*}{-4.33} & \multirow[t]{2}{*}{$<0.001$} \\
\hline & SD & 2.09 & 1.75 & & \\
\hline \multirow{2}{*}{$\begin{array}{l}\text { Analysis skills } \\
\text { in post-test } \\
(\max =10)\end{array}$} & Mean & 8.27 & 7.66 & \multirow[b]{2}{*}{-1.81} & \multirow[b]{2}{*}{ n.s. } \\
\hline & $\mathrm{SD}$ & 2.00 & 2.17 & & \\
\hline
\end{tabular}

According to Table 3, it is possible to see that the posterior visual analysis skills are not anymore statistically significant between high- and low-performing modellers $(\mathrm{Z}=-1.81 ; \mathrm{p}=$ n.s.). This precise result shows that modelling activities are very efficient for improving the visual analysis skills of learners especially when this initial level is low.

\section{Conclusion}

This study explores the modelling activity performances of collaborative and individual learners in a web-based environment. The research investigates also the influence of prior visual analysis skills on the modelling activities.

The following conclusions can be drawn by using the findings discussed previously:

- Individual workers make significantly more mistakes in the first modelling operation. Then, the following operations do not show any significant difference between the students who have learned individually or cooperatively. Therefore, as expected in our first hypothesis (i), there is a significant influence of collaborative work at the beginning of the modelling activities.

- The prior visual analysis skills are significantly higher for the high-performing modellers than for the lowperforming modellers. The initial level of visual analysis skills is an important factor for modelling activity outcomes as expected in our second hypothesis (ii).

- Modelling activities contribute to developing visual analysis skills in collaborative and individual learning settings, with low or high prior visual skills.
Educational implications concerning the environment Cell World can be extracted from these results: this web-based environment can be used in both cases - in small groups or individually. If some differences are apparent at the very beginning of the modelling activities with more effectiveness for cooperative groups, this effect weakens quickly probably due to the support provided by the environment (for instance the question prompts). Moreover, even for students with low prior level in visual analysis skills, the environment provides sufficient support to be efficient in developing these skills.

\section{Acknowledgements}

We particularly thank the teachers and students who participated in this study. The Estonian Research Mobility Scheme (ERMOS10) has supported this work in conjunction with the FP7 Marie Curie COFUND 'People' and Estonian Science Foundation grant 7739.

\section{References}

[1] Noroozi, O., Biemans, H. J. A., Busstra, M. C., Mulder, M., \& Chizari, M, "Differences in learning processes between successful and less successful students in computer-supported collaborative learning in the field of human nutrition and health," Computers in Human Behavior, 27(1), pp. 309-317, 2011.

[2] Stegmann, K., Weinberger, A., \& Fischer, F, "Facilitating argumentative knowledge construction with computersupported collaboration scripts," International Journal of Computer-Supported Collaborative Learning, 2(4), pp. 421-447, 2007.

[3] Raes, A., Schellens, T., De Wever,B., \& Vanderhoven, E, "Scaffolding information problem solving in web-based collaborative inquiry learning," Computers \& Education. 59(1), pp. 82-94, 2012.

[4] Kolloffel, B., Eysink, T. H., \& de Jong, T, "Comparing the effects of representational tools in collaborative and individual inquiry learning," International Journal of Computer-Supported Collaborative Learning, 6(2), pp. 223-251, 2011.

[5] Gijlers, H., \& de Jong, T, "Sharing and confronting propositions in collaborative inquiry learning," Cognition and Instruction, 27(3), pp. 239-268, 2009.

[6] http://pict.sdsu.edu/engauge21st.pdf.

[7] Buzaši Marganić, M, "Development visual literacy in digital environment", MIPRO, Proc. of the 33rd International Convention , pp. 1096-1098, 2010.

[8] Piksööt, J., \& Sarapuu, T, "Questioning Strategy for Supporting Students' Modeling Activities in the Virtual Learning Environment Cell World", Proc. of the IADIS International Conference e-Learning 2011, pp. 192-196, 2011.

[9] Pedaste, M., \& Sarapuu,T, "Developing an effective support system for inquiry learning in a web-based environment", Journal of Computer Assisted Learning, 22(1), pp. 47-62, 2006. 